\title{
Smoking and suicidality among adolescent psychiatric patients
}

\section{Mäkikyrö, Taru H.}

2004-03

Mäkikyrö , T H , Hakko , H H , Timonen , M J , Lappalainen , J A S , llomäki , R S , Marttunen , M J , Läksy , K \& Räsänen , P K 2004 , ' Smoking and suicidality among adolescent psychiatric patients ' , Journal of Adolescent Health , vol. 34 , no. 3 , pp. 250-253 . https://doi.org/10.1016/j.jadohealth.2003.06.008

http://hdl.handle.net/10138/297742

https://doi.org/10.1016/j.jadohealth.2003.06.008

publishedVersion

Downloaded from Helda, University of Helsinki institutional repository.

This is an electronic reprint of the original article.

This reprint may differ from the original in pagination and typographic detail.

Please cite the original version. 


\title{
Smoking and Suicidality Among Adolescent Psychiatric Patients
}

\author{
TARU H. MÄKIKYRÖ, M.D., Ph.D., HELINÄ H. HAKKO, Ph.D., MARKKU J. TIMONEN, M.D., \\ JAAKKO A. S. LAPPALAINEN, M.D., Ph.D., RISTO S. ILOMÄKI, B.M., \\ MAURI J. MARTTUNEN, M.D., Ph.D., KRISTIAN LÄKSY, M.D., Ph.D., AND \\ PIRKKO K. RÄSÄNEN, M.D., Ph.D.
}

Purpose: To investigate the relationship between smoking and suicidality among adolescent psychiatric patients in Finland.

Methods: Data from 157 patients (aged 12-17 years) admitted to inpatient psychiatric hospitalization between April 2001 and July 2002 were collected. Logistic regression analyses were used to examine the association between regular daily smoking and suicidality. The data were adjusted for several sociodemographic and clinical characteristics.

Results: The results showed over four-fold risk for definite and/or life-threatening suicide attempts among smoking adolescents in inpatient psychiatric facility compared with nonsmoking ones (OR 4.33, 95\% CI 1.2315.20). Also, the smoking adolescents had three times greater risk for occasional (OR 3.32, 95\% CI 1.09-10.10) or frequent (OR 3.00, 95\% CI 1.08-10.10) self-mutilation. Suicidality was more common among girls than boys and among those adolescents who suffered from depression.

Conclusions: Among teens hospitalized for psychiatric illnesses, daily smoking was significantly related to suicide attempts and self-mutilation, even after controlling for several confounding factors, including psychiatric diagnosis. (C) Society for Adolescent Medicine, 2004

From the Department of Psychiatry, University of Oulu, Oulu, Finland (T.H.M., H.H.H., M.J.T., R.S.I., K.L.); Department of Psychiatry, Oulu University Hospital, Oulu, Finland (T.H.M., H.H.H., K.L., P.K.R.); Oulu Health Center, Oulu, Finland (M.J.T.); Department of Psychiatry, Yale University, School of Medicine, New Haven Connecticut (J.A.S.L.); and Department of Psychiatry, University of Helsinki, Helsinki, Finland (M.J.M.).

Address correspondence to: Dr. Taru H. Mäkikyrö, Department of Psychiatry, Oulu University Hospital, Box 26, 90029 OYS, Oulu,

Finland.E-mail: taru.makikyro@ppshp.fi

Manuscript accepted June 12, 2003.
KEY WORDS:

Adolescent

Gender differences

Psychiatric patient

Self-mutilation

Smoking

Suicidality

Finland

Several studies in adults, adolescents, and children have revealed a positive relationship between smoking and suicidality. Most of these studies, however, have focused on nonclinical samples [1-5]. The association between smoking and suicidality has been studied among adult psychiatric patients [6,7], but no previous studies focus on adolescent psychiatric inpatients. Recently, adult patients with a history of self-mutilation were reported to be at a greater risk for suicide, and, to underestimate the lethality of their attempts [8]. The association between smoking and self-mutilation has not been analyzed in earlier studies. We also, therefore, studied whether regular smoking increases the risk for self-mutilation among adolescents who were aged 17 years or younger.

\section{Methods}

The STUDY-70-project was initiated to examine the association of various psychosocial risk factors to the outcomes of severe psychiatric and substance use disorders among hospital-treated adolescents aged 12-17 years. The study sample consisted of adoles- 
cents admitted to the Oulu University Hospital Department of Psychiatry between April 2001 and July 2002. Of the total of 198 adolescents admitted, 11 were excluded ( 9 mental retardation, one brain organic disorder, one over 18 years. Of the 187 patients, $84 \%$ ( $\mathrm{n}=157$; boys 70 , girls 87 ) gave a written informed consent and were enrolled in the study. A total of $97.5 \%(n=153)$ were Caucasian adolescents. The study protocol was approved by the Ethics Committee of the Faculty of Medicine, University of Oulu (Finland).

The subjects were interviewed by the patient's treating physician using the Schedule for Affective Disorder and Schizophrenia for School-Age Children Present and Lifetime (K-SADS-PL) to obtain DSM-IV diagnoses [9], and the information about regular daily smoking (at least one cigarette per day). Data regarding the present and lifetime suicidal ideation ("none," "occasional," "frequent"), severity of the suicide attempts ("none," "ambivalent/mild," "definite/life-threatening"), and histories of self-mutilation ["no intention to die" (frequency variable: "none," "occasional," "frequent")] were collected from the K-SADS-PL.

Association between smoking and suicidality was assessed using logistic regression analyses after adjusting for adolescent's gender, age, family type (two biological parents, other type of family), school achievement (mean of grades), parental substance abuse (mother's or father's substance abuse, "yes"/ "no"), psychiatric diagnosis [drug dependence/ abuse $(46.5 \%$ of the study population), conduct disorder $(45.2 \%)$, depression $(42.0 \%)$, anxiety disorders $(32.5 \%)$, psychoses $(10.8 \%)$ and other disorders $(4.5 \%)]$, and mother's occupation. To assess the socioeconomic status (SES) of an adolescent, mother's occupation ( $67.8 \%$ educated) was used, because $33 \%$ of the subjects had grown up with both parents and only $7 \%$ with their father present. All analyses were carried out using SPSS version 10 for Windows [10].

\section{Results}

Of the total study population $79.0 \%(n=124)$ were regular daily smokers (at least one cigarette per day). The proportion of smokers did not differ significantly between genders.

The rate of frequent suicidal ideation was significantly higher for girls (70.1\%) than for boys (40.1\%) $\left(\chi^{2}=24.9, \mathrm{df}=2, p<.001\right)$. Suicide attempts were more common among the girls $(48.3 \%)$ as compared with the boys $(17.1 \%)\left(\chi^{2}=23.3, \mathrm{df}=2, p<.001\right)$.
Self-mutilative behavior was observed more frequently among the girls $(48.3 \%)$ than the boys $(25.7 \%)\left(\chi^{2}=15.5, \mathrm{df}=2, p<.001\right)$. When analyzing differences between smoking and nonsmoking adolescents, the only significant difference was that the girls who smoked had higher proportion of frequent self-mutilation compared with the nonsmoking girls (52.2\% vs. $\left.35.0 \% ; \chi^{2}=7.1, \mathrm{df}=2, p=.029\right)$.

In logistic regression analyses (Table 1), regular daily smoking was associated with definite or lifethreatening suicide attempts, as well as with both occasional and frequent self-mutilation. Suicide attempts and frequent self-mutilation were more common among the girls and adolescents suffering from depression. No association between smoking and suicidal ideation was detected in the total sample, but significantly increased risk for suicidal ideation was found among girls and among those subjects suffering from depression.

\section{Discussion}

In this study, we found evidence that regular smoking is significantly related to increased risk for suicide attempts in a sample of adolescents undergoing inpatient psychiatric hospitalization. This association was positive even after adjusting for the presence of psychiatric disorders and sociodemographic variables. A novel finding in our study is that smoking was not only associated with definite suicide attempts, but also with self-mutilative behavior.

However, the direction of the causality between smoking, suicide attempts, and self-mutilation remains unclear. The smoking adolescents who attempt suicide or mutilate themselves may have impaired catecholaminergic and 5-HT function in CNS, leading to more impulsive and aggressive behavior than the adolescents who have suicidal ideation alone [11]. Exposure to nicotine during adolescence causes changes in the CNS noradrenergic, dopaminergic, and serotonergic (5HT) function [12,13]. Thus, it is tempting to speculate that adolescents who smoke may be attempting to "self-medicate" their feelings of depression, despair, impulsivity, and suicidality. To our understanding, no conclusive evidence has been presented suggesting that smoking per se would cause suicide attempts and selfmutilation.

The majority of the adolescents in this sample were smokers. The significance of the smoking habit of the adolescent psychiatric patients is often shadowed by their other severe problems, which may 


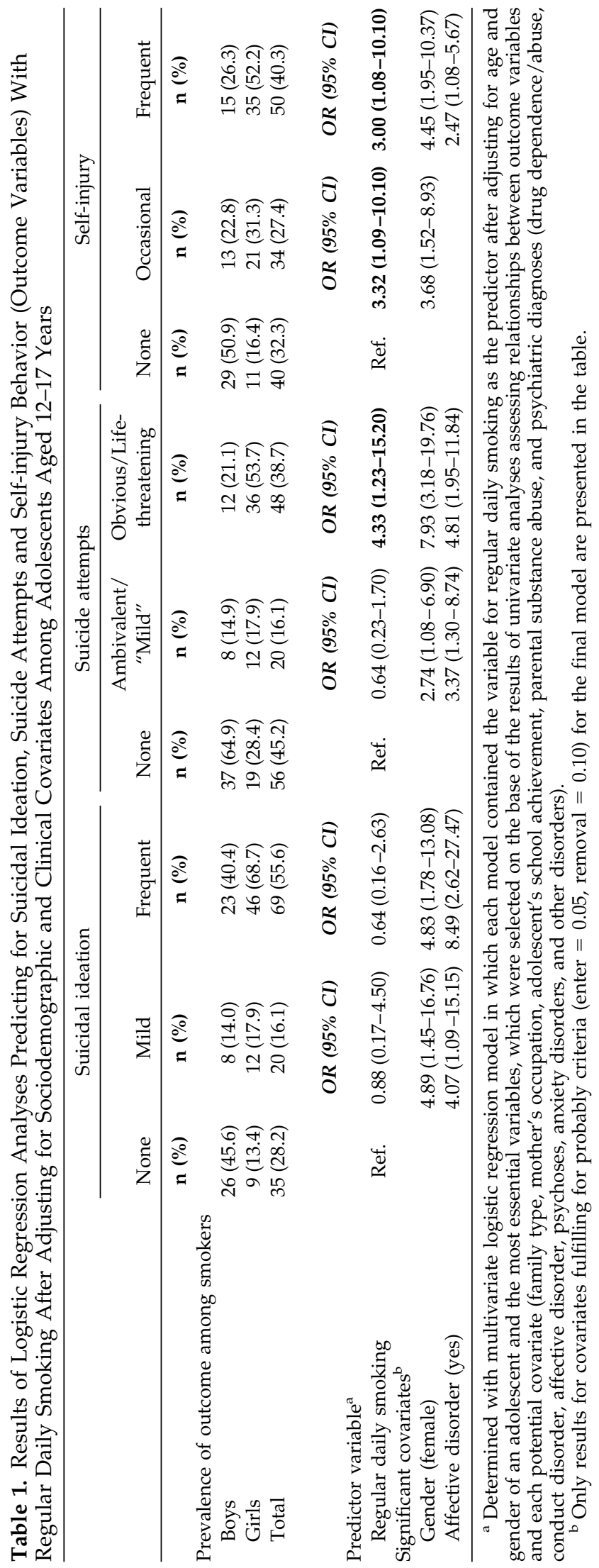

preclude attention to smoking. Smoking cessation should be supported because it may play a role in recovery from suicidality [14].

A surprisingly high proportion of the girls who smoked reported self-mutilative behavior. Suicidality among individuals with self-mutilative behaviors has often been underestimated and interpreted as manipulative or attention-seeking behavior. A recent study by Stanley et al [8] indicated that the number of suicide attempts or the lethality of the attempts did not differ between patients with and without a history of self-mutilation. Self-mutilators commonly underestimate the lethality of their suicidal behavior and view death with less finality. In our study, the frequency of self-mutilative behavior among the young adolescent smoking girls is alarming and may indicate a greater risk for suicide in the future.

Depression, anxiety, disruptive disorders, and substance abuse/dependence have been found to be risk factors for attempted and completed suicides among teenagers [15-17]. Many authors have described that young women demonstrate more suicidal gestures, whereas young men have more suicide completions [18-20]. We also found an increased risk for suicidal ideation, suicide attempts, and frequent self-mutilative behavior among girls. Individuals with depression were also at a higher risk for suicide attempt and self-mutilation. In accordance with some previous studies [2,6], smoking in this study was independently associated with suicidality even after controlling for psychiatric diagnoses.

\section{Limitations}

The limitations of this study are that our sample consisted of hospitalized inpatients, which limits the generalization of our findings for all adolescents. Secondly, information on smoking and suicidality might be underestimated, although structured interviews and multiple reporters by K-SADS-PL diminish this bias.

\section{Conclusions}

This study extends the earlier research on the association between smoking and suicidality into the realm of adolescent psychiatric inpatients. The results of our study suggest that direct relationship may exist between smoking and suicidality. However, smoking in adolescence may be one part of other health-risk behaviors $[5,20]$. Thus, associations between smoking and suicidality may be noncausal 
and reflect the presence of other risk factors that are related to increased risk of suicidality. However, without profound investigation, many other healthrisk behaviors (e.g., family dysfunction or substance abuse) may pass notice even from health care professionals. Regular smoking among adolescent psychiatric patients is an indicator of increased adolescent suicidality and, therefore, easy to notice. Paying attention to smoking may facilitate identification of those adolescents who are at risk for suicide, which may help them to receive professional help in time.

This study received support from the Päivikki and Sakari Sohlberg Foundation, the Finnish Psychiatric Association, Ethel F. Donaghue Women's Health Investigator Program at Yale, Alcoholic Beverage Medical Research Foundation (ABMRF), and VA MIRECC. We thank the staff of the adolescent unit 70 of the Oulu University Hospital for data collection, and all the adolescents who participated in this study.

\section{References}

1. Angst J, Clayton PJ. Personality, smoking and suicide: A prospective study. J Affect Disord 1998;51:55-62.

2. King RA, Schwab-Stone M, Flisher AJ, et al. Psychosocial and risk behavior correlates of youth suicide attempts and suicidal ideation. J Am Acad Child Adolesc Psychiatry 2001;40:837-46.

3. Miller M, Hemenway D, Rimm E. Cigarettes and suicide: A prospective study of 50,000 men. Am J Public Health 2000;90: 768-73.

4. Tanskanen A, Tuomilehto J, Viinamäki H, et al. Smoking and the risk of suicide. Acta Psychiatr Scand 2000;101:243-5.

5. Tomori M, Zalar B, Kores Plesničar B, et al. Smoking in relation to psychosocial risk factors in adolescent. Eur Child Adolesc Psychiatry 2001;10:143-50.

6. Mann JJ, Waternaux C, Haas GL, et al. Toward a clinical model of suicidal behavior in psychiatric patients. Am J Psychiatry 1999;156:181-9.
7. Tanskanen A, Viinamäki H, Hintikka J, et al. Smoking and suicidality among psychiatric patients. Am J Psychiatry 1998; 155:129-30.

8. Stanley B, Gameroff MJ, Michalsen V, et al. Are suicide attempters who self-mutilate a unique population? Am J Psychiatry 2001;158:427-32.

9. Kaufman J, Birmaher B, Brent D, et al. Schedule for Affective Disorders and Schizophrenia for School-Age ChildrenPresent and Lifetime Version (K-SADS-PL): Initial reliability and validity data. J Am Acad Child Adolesc Psychiatry 1997;36:980-8.

10. Norusis JE. SPSS for Windows. Advanced Statistics. Release 6. Chicago, IL: SPSS Inc Corp.

11. Linnoila VM, Virkkunen M. Aggression, suicidality, and serotonin. J Clin Psychiatry 1992;53(Suppl):46-51.

12. Trauth JA, Seidler FJ, Ali SF, et al. Adolescent nicotine exposure produces immediate and long-term changes in CNS noradrenergic and dopaminergic function. Brain Res 2001;892: 269-80.

13. Xu Z, Seidler F, Cousins M, et al. Adolescent nicotine administration alters serotonin receptors and cell signaling mediated through adenyl cyclase. Brain Res 2002;951:280-292.

14. Hintikka J, Pesonen T, Saarinen P, et al. Suicidal ideation in the Finnish general population. A 12-month follow-up study. Soc Psychiatry Psychiatr Epidemiol 2001;36:590-4.

15. Gould M, King R, Greenwald S, et al. Psychopathology associated with suicidal ideation and attempts among children and adolescents. J Am Acad Child Adolesc Psychiatry 1998; 37:915-23.

16. Marttunen MJ, Aro HM, Henriksson MM, et al. Mental disorders in adolescent suicide. Arch Gen Psychiatry 1991;48: 834-9.

17. Shaffer D, Gould M, Fisher P, et al. Psychiatric diagnosis in child and adolescent suicide. Arch Gen Psychiatry 1996;53: 339-48.

18. Husain SA. Current perspective on the role of psychological factors in adolescent suicide. Psychiatr Ann 1990;32:122-7.

19. King CA, Hill EM, Naylor M, et al. Alcohol consumption in relation to other predictors of suicidality among adolescent girls. J Am Acad Child Adolesc Psychiatry 1993;32:82-8.

20. Woods ER, Lin YG, Middleman A, et al. The associations of suicide attempts in adolescents. Pediatrics 1997;99:791-6. 